\title{
BMJ Open Selling falsehoods? A cross-sectional study of Canadian naturopathy, homeopathy, chiropractic and acupuncture clinic website claims relating to allergy and asthma
}

\author{
Blake Murdoch, ${ }^{1}$ Stuart Carr, ${ }^{2}$ Timothy Caulfield ${ }^{1,3}$
}

To cite: Murdoch B, Carr S, Caulfield T. Selling falsehoods? A crosssectional study of Canadian naturopathy, homeopathy, chiropractic and acupuncture clinic website claims relating to allergy and asthma. BMJ Open 2016;6:e014028. doi:10.1136/bmjopen-2016014028

- Prepublication history for this paper is available online. To view these files please visit the journal online (http://dx.doi.org/10.1136/ bmjopen-2016-014028).

Received 26 August 2016 Revised 17 October 2016 Accepted 25 November 2016

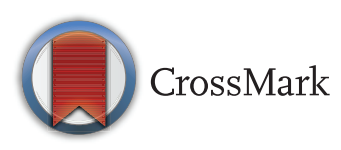

${ }^{1}$ Health Law Institute, University of Alberta, Edmonton, Alberta, Canada 2Department of Pediatrics, University of Alberta, Edmonton, Alberta, Canada ${ }^{3}$ Law Centre, University of Alberta, Edmonton, Alberta, Canada

\section{Correspondence to} Timothy Caulfield; caulfield@ualberta.ca

\section{ABSTRACT}

Objective: To identify the frequency and qualitative characteristics of marketing claims made by Canadian chiropractors, naturopaths, homeopaths and acupuncturists relating to the diagnosis and treatment of allergy and asthma.

Design: Cross-sectional study.

Setting: Canada.

Data set: 392 chiropractic, naturopathic, homeopathic and acupuncture clinic websites located in 10 of the largest metropolitan areas in Canada, as identified using 400 Google search results. Duplicates were not excluded from data analysis.

Main outcome measures: Mention of allergy, sensitivity or asthma, claim of ability to diagnose allergy, sensitivity or asthma, claim of ability to treat allergy, sensitivity or asthma, and claim of allergy, sensitivity or asthma treatment efficacy. Tests and treatments promoted were noted as qualitative examples.

Results: Naturopath clinic websites have the highest rates of advertising at least one of diagnosis, treatment or efficacy for allergy or sensitivity (85\%) and asthma (64\%), followed by acupuncturists $(68 \%$ and $53 \%$, respectively), homeopaths (60\% and $54 \%$ ) and chiropractors (33\% and $38 \%$ ). Search results from Vancouver, British Columbia were most likely to advertise at least one of diagnosis, treatment or efficacy for allergy or sensitivity $(72.5 \%)$ and asthma $(62.5 \%)$, and results from London, Ontario were least likely ( $50 \%$ and $40 \%$, respectively). Of the interventions advertised, few are scientifically supported; the majority lack evidence of efficacy, and some are potentially harmful.

Conclusions: The majority of alternative healthcare clinics studied advertised interventions for allergy and asthma. Many offerings are unproven. A policy response may be warranted in order to safeguard the public interest.

\section{INTRODUCTION}

Complementary and alternative medicine (CAM) is popular in Canada. Government

\section{Strengths and limitations of this study}

- The marketing claims of complementary and alternative medicine practitioners are understudied, and given the popularity of such practitioners, it is in the public interest to better understand these claims.

- The public health burden caused by asthma and allergies is significant, and understanding the frequency and types of related interventions offered by alternative practitioners can help to determine what public health benefit and/or harm accrues.

- Owing to the straightforward methods and manner in which the relevant claims, services and products are represented on the studied websites, there was little need for coders to make subjective interpretations of website content; this increases the reliability of the results.

- Limitations of the study include a regional restriction to Canada, an English language bias, a restriction to studying only four types of alternative practitioners, an inability to search imagebased text on websites due to the use of automated domain searches, an approach that does not allow more complex comparisons between jurisdictions with different regulatory frameworks, and an inability to measure the public exposure of each website.

data from 2008 indicate that over $70 \%$ of Canadians use some form of CAM. ${ }^{1}$ In 2006, a study found that the most popular CAM providers in Canada were chiropractors (40\% of Canadians use during their lifetimes), acupuncturists (17\%), naturopaths $(9 \%)$ and homeopaths $(9 \%) .^{2}$ American data suggest that in 2012 Americans spent $\sim \$ 30.2$ billion on CAM, with adults spending an average of $\$ 514$ on CAM practitioner visits, supplements and self-care approaches. ${ }^{3}$ CAM clinics are abundant in each major Canadian metropolitan centre and many of those clinics engage in advertising online. 
CAM practitioners are increasingly being framed as potential primary care providers. ${ }^{45}$ The scope of conditions claimed to be treatable by CAM providers can be very broad, and interventions are often presented as scientifically legitimate. ${ }^{6-8}$ This has resulted in controversy over policy. In Australia, for example, misleading claims by chiropractors have resulted in widespread calls to dismantle the Chiropractic Board of Australia for its failure to police its members; ${ }^{9-12}$ here in Canada, the ability of naturopaths to effectively self-regulate has recently been questioned. $^{13}$

Claims by CAM providers as to the ability to diagnose and treat allergy and asthma are understudied. A 2011 study found that allergy testing and treatment were the most common interventions advertised on Canadian naturopath clinic websites. ${ }^{7}$ Allergy and asthma present a significant public health challenge in Canada. ${ }^{14}$ Allergies affect over a third of the present adolescent population, ${ }^{15} 16$ and asthma affects about $10-15 \%$ while being the most common chronic childhood condition resulting in healthcare usage. ${ }^{17}$ Indeed, asthma inflicts a heavy economic burden of tens to hundreds of millions of dollars per province per year, depending on the province. ${ }^{14}$ Canadian data on the economic costs of allergy are somewhat lacking, but costs are almost certainly very high. In the USA, a 2013 study estimated the economic cost of childhood food allergy alone at $\$ 24.8$ billion per year. ${ }^{18}$ A similar 2014 study of all allergic diseases in the European Union estimated an annual cost of between $€ 55$ and $€ 151$ billion. ${ }^{19}$ Given the high public health burden of these conditions, it is important to ensure that effective, evidence-based interventions are systematically offered to the public.

The popular press and social media have contributed to widespread beliefs regarding the existence of common sensitivities to foods like gluten, ${ }^{20}{ }^{21}$ even though 'sensitivity' is, from a clinical perspective, an undefined and ambiguous term. Given the rising incidence and profile of allergies and asthma, ${ }^{22}$ it is no surprise that CAM practitioners have successfully catered to these conditions. Many online advertisements claim that chiropractors, naturopaths, acupuncturists and homeopaths can diagnose and treat allergy, sensitivity and asthma. Clinic websites present a valuable opportunity to investigate the frequency at which CAM providers engage in such advertisement, as well as the claims they make. In this study, we analysed the advertising content of 392 Canadian CAM clinic websites in order to determine what kinds of claims were made about allergy and asthma and their frequency.

\section{METHODS}

In order to build a sample of CAM practitioners' websites for analysis, the top 10 most populous Canadian metropolitan areas were selected according to 2015 data from Statistics Canada. Quebec City was excluded from the study due to an abundance of strictly French language clinic websites that would have caused coding issues. Google searches were then performed using the web tool ISearchFrom.com in order to emulate searching from each respective city, and to remove the geographical search biases that would normally arise given the actual location of the searcher (Edmonton, Alberta). This tool also disabled Google's personalised results functionality, ensuring generalisable findings. Search terms were of the form (city practitioner), for example, Toronto chiropractor, Calgary naturopath, Vancouver homeopath, Hamilton acupuncturist, etc.

Search result websites were then collected. Given the 10 metropolitan areas, four disciplines and our commitment to finding the top 10 clinic results for each search, a final sample of 400 search results was collected between March and April of 2016. Only links to clinics or practitioner websites were included (colleges and regulatory bodies were excluded). Advertisements were excluded. Google presented three Google Maps business results at the top of each search; results from these were included if they included a link to a clinic or practitioner website. Websites for practitioners or clinics from countries other than Canada were excluded, but Canadian clinic websites from cities other than the search city were included. Duplicate links to the same web domain were excluded in the same search, but were not excluded across different searches; this is because the study was designed to focus on what people are actually exposed to when searching. Eight sets of website duplicates were found, meaning there were 392 unique websites. Duplicates were counted twice in data analysis.

Once the list of domains was collected, websites were analysed between April and June 2016, using Google domain search to look for instances of the terms sensitivity, allergy and asthma. For example: allergy site: backinbalanceclinic.com. Google stemming technology automatically incudes instances of similar words to the search term: for example, allergic, allergen. Owing to the nature of the Google search analysis, unsearchable text, such as text embedded in image form, was excluded.

Results of domain searches were then analysed to determine: (1) whether asthma, allergy or sensitivity was mentioned; (2) whether claims were made as to the ability to diagnose these conditions; (3) whether claims were made as to the ability to treat these conditions (eg, "The naturopaths at our clinic treat allergies", no explicit statement as to the treatment working is required in this instance); and (4) whether statements were made about the efficacy of the CAM practices in treating these conditions (eg, "Homeopathy works for asthma", no explicit statement as to the clinic actually offering the intervention is required in this instance). Commonly, a single statement would constitute both a claim of treatment and a claim of efficacy (eg, "We can treat allergies with chiropractic, which has been shown to work"). Excerpts were copied for the purpose of sharing qualitative examples. 
Table 1 Findings by clinic category, numerical counts and total percentages

\begin{tabular}{|c|c|c|c|c|c|c|c|c|c|c|}
\hline \multirow[b]{2}{*}{ Mention or claim } & \multicolumn{2}{|c|}{$\begin{array}{l}\text { Total } \\
\text { percentages }\end{array}$} & \multicolumn{2}{|c|}{ Chiropractor } & \multicolumn{2}{|c|}{ Naturopath } & \multicolumn{2}{|c|}{ Homeopath } & \multicolumn{2}{|c|}{ Acupuncturist } \\
\hline & Yes & No & Yes & No & Yes & No & Yes & No & Yes & No \\
\hline Allergy mention & 67.50 & 32.50 & 55 & 45 & 85 & 15 & 69 & 31 & 61 & 39 \\
\hline Allergy diagnosis & 25.25 & 74.75 & 11 & 89 & 65 & 35 & 22 & 78 & 3 & 97 \\
\hline Allergy treatment & 56.25 & 43.75 & 30 & 70 & 75 & 25 & 62 & 38 & 58 & 42 \\
\hline Efficacy for allergy & 18.00 & 82.00 & 6 & 94 & 29 & 71 & 23 & 77 & 14 & 86 \\
\hline Sensitivity mention & 37.50 & 62.50 & 48 & 52 & 73 & 27 & 24 & 76 & 5 & 95 \\
\hline Sensitivity diagnosis & 17.50 & 82.50 & 2 & 98 & 53 & 47 & 14 & 86 & 1 & 99 \\
\hline Sensitivity treatment & 12.00 & 88.00 & 3 & 97 & 34 & 66 & 9 & 91 & 2 & 98 \\
\hline Efficacy for sensitivity & 2.50 & 97.50 & 0 & 100 & 7 & 93 & 3 & 97 & 0 & 100 \\
\hline Asthma mention & 60.75 & 39.25 & 56 & 44 & 74 & 26 & 57 & 43 & 56 & 44 \\
\hline Asthma diagnosis & 2.50 & 97.50 & 3 & 97 & 5 & 95 & 2 & 98 & 0 & 100 \\
\hline Asthma treatment & 52.00 & 48.00 & 38 & 62 & 63 & 37 & 53 & 47 & 54 & 46 \\
\hline Efficacy for asthma & 13.00 & 87.00 & 10 & 90 & 14 & 86 & 16 & 84 & 12 & 88 \\
\hline
\end{tabular}

Coding required limited subjective interpretation, but in order to assess accuracy we had a Health Law Institute associate with no prior connection to the study design perform basic quality assurance on five coding samples, resulting in $100 \%$ accuracy. The data were collected in Microsoft Excel; no complex statistical analysis was undertaken, and analysis was limited to conversion to various percentages.

\section{RESULTS}

Our results show that a significant portion of CAM clinics studied advertised services relating to the diagnosis and/or the treatment of allergy and/or asthma. Of the four disciplines studied, naturopath clinic websites have the highest rates of advertising at least one of diagnosis, treatment or efficacy for allergy or sensitivity $(85 \%)$ and asthma (64\%), followed by acupuncturists $(68 \%$ and $53 \%$, respectively), homeopaths $(60 \%$ and $54 \%)$ and chiropractors (33\% and 38\%). Tables 1 and 2 and figures 1 and 2 show these data.

In addition, data were arranged by search city, as shown in tables 3 and 4. Clinic websites derived from Vancouver search results had the highest frequency of claims relating to at least one of diagnosis, treatment or efficacy for both allergy/sensitivity $(72.50 \%)$ and asthma $(62.50 \%)$. London, Ontario, had the lowest frequency of the same for both allergy/sensitivity $(50 \%)$ and asthma (40\%—tied with Winnipeg).

Diagnosis claims were less frequent than treatment claims for allergy $(25.25 \%$ and $56.25 \%$, respectively) and asthma $(2.5 \%$ and $52 \%)$, and were more frequent than treatment claims for sensitivity $(17.5 \%$ and $12 \%)$. Efficacy claims were only possible where treatment claims already existed. As such, we can calculate that $32 \%$ of treatment claims for allergy were accompanied by additional explicit claims as to treatment efficacy; this was also true for $20.83 \%$ of sensitivity treatment claims and $25 \%$ of allergy treatment claims. Aside from these explicit claims of efficacy, one could logically conclude
Table 2 Percentage of websites claiming at least one of diagnosis, treatment or efficacy for allergy/sensitivity or asthma, by clinic category

\begin{tabular}{lll}
\hline Clinic category & Allergy or sensitivity & Asthma \\
\hline Chiropractor & 33 & 38 \\
Naturopath & 85 & 64 \\
Homeopath & 60 & 54 \\
Acupuncturist & 68 & 53 \\
\hline
\end{tabular}

that advertising a treatment implies that the treatment is efficacious.

Table 5 provides a sampling of the tests and treatments recommended for allergy, sensitivity and asthma on the clinic websites studied. Coders noted the presence of disclaimers on some clinic websites, which seemed to acknowledge the lack of scientific validity underlying the approaches advertised. For example: "Disclaimer: [Bioenergetic Intolerance Elimination] practitioners are not medical doctors and do not use medical diagnostic or treatment procedures. The services performed by BIE practitioners are at all times restricted to consultation on the subject of nutritional matters and the BIB modality [...] All services provided are done for experimental or educational purposes only and do not involve the diagnosing, curing, prognosticating, treatment or prescribing of remedies for the treatment of disease [...]" (thesageclinic.com).

Claims were presented with a variety of wording. Examples of claims of diagnosis include: "Dr. Muradov may use blood tests, food allergy testing, biofeedback analysis and physical exam to aid in diagnosis and treatment" (drericmuradov.com), "Assessment and Diagnostic Services: Food Allergy Testing" (850heal. com), and "In her daily practice, Jennifer diagnoses and treats all health condition [sic] from eczema and asthma to MS and cancer" (ottawanaturopathic.ca). Examples of claims of treatment include: "Common Conditions 


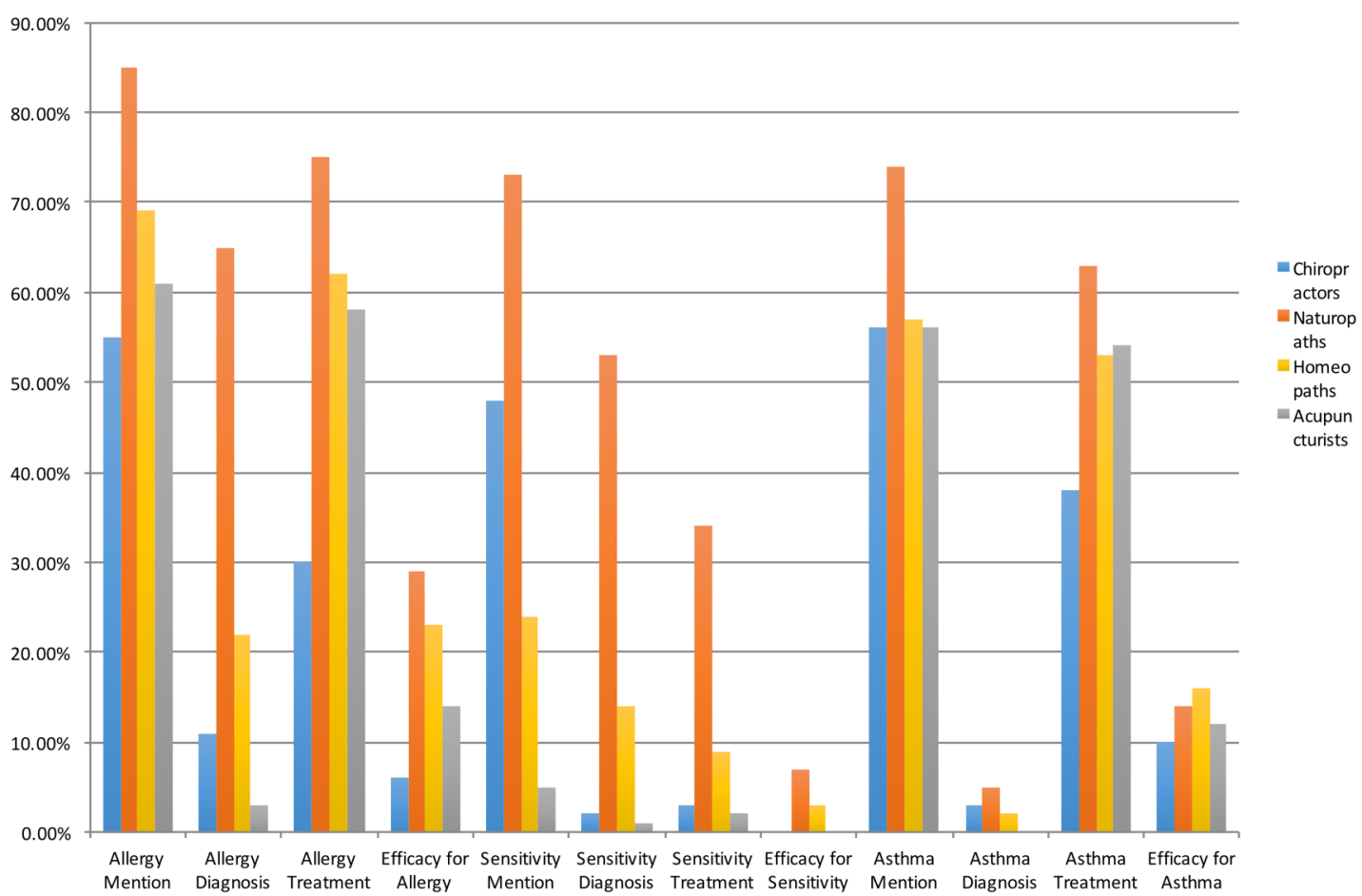

Figure 1 Percentage of CAM clinic websites making specific mentions or claims. For all website content categories except 'efficacy for asthma', naturopaths have the highest rate of mention or claim. Blue=chiropractors; orange=naturopaths; yellow=homeopaths; grey=acupuncturists. CAM, complementary and alternative medicine.

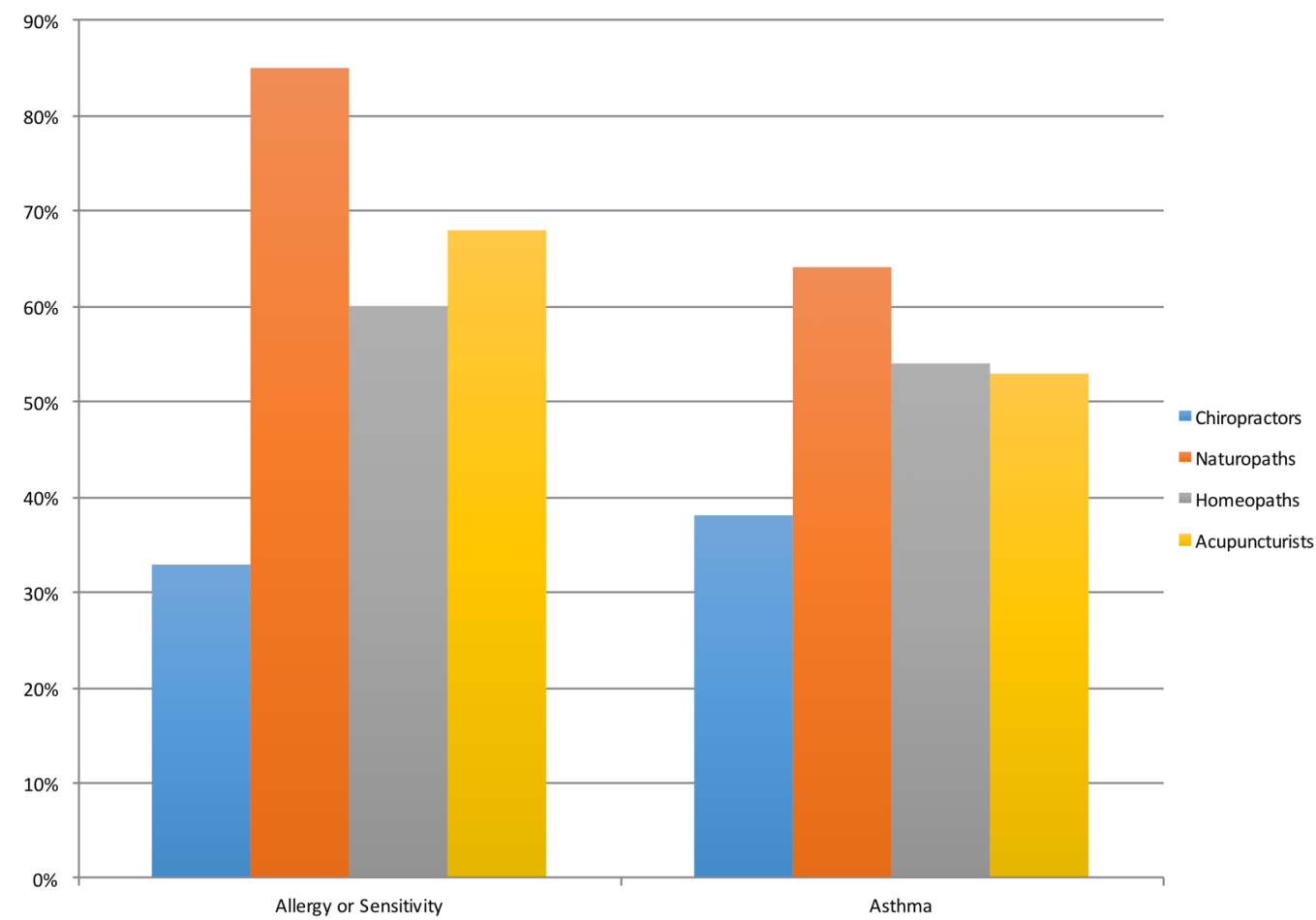

Figure 2 Percentage of alternative medicine clinic websites advertising at least one of diagnosis, treatment or efficacy for allergy/sensitivity or asthma. Presenting the data in this way demonstrates that the Canadian naturopath, homeopath and acupuncturist websites studied have $>50 \%$ rates of making at least one health-related claim for both allergy/sensitivity and asthma. Blue=chiropractors; orange=naturopaths; grey=homeopaths; yellow=acupuncturists. 
Table 3 Findings by search city

\begin{tabular}{|c|c|c|c|c|c|c|c|c|c|c|}
\hline \multirow[b]{2}{*}{ Mention or claim } & \multicolumn{2}{|c|}{ Calgary (\%) } & \multicolumn{2}{|c|}{ Edmonton (\%) } & \multicolumn{2}{|c|}{ Hamilton (\%) } & \multicolumn{2}{|c|}{ Kitchener (\%) } & \multicolumn{2}{|c|}{ London (\%) } \\
\hline & Yes & No & Yes & No & Yes & No & Yes & No & Yes & No \\
\hline Allergy mention & 67.5 & 32.5 & 75.0 & 25.0 & 65.0 & 35.0 & 75.0 & 25.0 & 55.0 & 45.0 \\
\hline Allergy diagnosis & 32.5 & 67.5 & 32.5 & 67.5 & 17.5 & 82.5 & 30.0 & 70.0 & 20.0 & 80.0 \\
\hline Allergy treatment & 60.0 & 42.5 & 57.5 & 42.5 & 55.0 & 45.0 & 52.5 & 47.5 & 50.0 & 50.0 \\
\hline Efficacy for allergy & 15.0 & 85.0 & 25.0 & 75.0 & 20.0 & 80.0 & 17.5 & 82.5 & 12.5 & 87.5 \\
\hline Sensitivity mention & 42.5 & 55.0 & 35.0 & 65.0 & 37.5 & 62.5 & 42.5 & 57.5 & 22.5 & 77.5 \\
\hline Sensitivity diagnosis & 27.5 & 72.5 & 20.0 & 80.0 & 17.5 & 82.5 & 22.5 & 77.5 & 10.0 & 90.0 \\
\hline Sensitivity treatment & 22.5 & 77.5 & 12.5 & 87.5 & 22.5 & 77.5 & 5.0 & 95.0 & 0.0 & 100.0 \\
\hline Efficacy for sensitivity & 5.0 & 95.0 & 2.5 & 97.5 & 0.0 & 100.0 & 0.0 & 100.0 & 0.0 & 100.0 \\
\hline Asthma mention & 62.5 & 37.5 & 65.0 & 35.0 & 67.5 & 32.5 & 60.0 & 40.0 & 47.5 & 52.5 \\
\hline Asthma diagnosis & 2.5 & 97.5 & 5.0 & 95.0 & 5.0 & 95.0 & 0.0 & 100.0 & 5.0 & 95.0 \\
\hline Asthma treatment & 60.0 & 42.5 & 55.0 & 45.0 & 57.5 & 42.5 & 45.0 & 55.0 & 40.0 & 60.0 \\
\hline \multirow[t]{2}{*}{ Efficacy for asthma } & 7.5 & 92.5 & 22.5 & 77.5 & 10.0 & 90.0 & 10.0 & 90.0 & 12.5 & 87.5 \\
\hline & \multicolumn{2}{|c|}{ Montreal } & \multicolumn{2}{|c|}{ Ottawa } & \multicolumn{2}{|c|}{ Toronto } & \multicolumn{2}{|c|}{ Vancouver } & \multicolumn{2}{|c|}{ Winnipeg } \\
\hline Mention or claim & Yes & No & Yes & No & Yes & No & Yes & No & Yes & No \\
\hline Allergy mention & 55.0 & 45.0 & 72.5 & 27.5 & 72.5 & 27.5 & 72.5 & 27.5 & 65.0 & 35.0 \\
\hline Allergy diagnosis & 17.5 & 82.5 & 22.5 & 77.5 & 30.0 & 70.0 & 25.0 & 75.0 & 25.0 & 75.0 \\
\hline Allergy treatment & 55.0 & 45.0 & 57.5 & 42.5 & 55.0 & 45.0 & 67.5 & 32.5 & 52.5 & 47.5 \\
\hline Efficacy for allergy & 12.5 & 87.5 & 20.0 & 80.0 & 15.0 & 85.0 & 32.5 & 67.5 & 10.0 & 90.0 \\
\hline Sensitivity mention & 22.5 & 77.5 & 50.0 & 50.0 & 40.0 & 60.0 & 50.0 & 50.0 & 32.5 & 67.5 \\
\hline Sensitivity diagnosis & 5.0 & 95.0 & 25.0 & 75.0 & 20.0 & 80.0 & 22.5 & 77.5 & 5.0 & 95.0 \\
\hline Sensitivity treatment & 5.0 & 95.0 & 15.0 & 85.0 & 20.0 & 80.0 & 12.5 & 87.5 & 5.0 & 95.0 \\
\hline Efficacy for sensitivity & 0.0 & 100.0 & 10.0 & 90.0 & 5.0 & 95.0 & 2.5 & 97.5 & 0.0 & 100.0 \\
\hline Asthma mention & 57.5 & 42.5 & 67.5 & 32.5 & 62.5 & 37.5 & 67.5 & 32.5 & 50.0 & 50.0 \\
\hline Asthma diagnosis & 0.0 & 100.0 & 0.0 & 100.0 & 2.5 & 97.5 & 5.0 & 95.0 & 0.0 & 100.0 \\
\hline Asthma treatment & 55.0 & 45.0 & 55.0 & 45.0 & 52.5 & 47.5 & 60.0 & 40.0 & 40.0 & 60.0 \\
\hline Efficacy for asthma & 5.0 & 95.0 & 17.5 & 82.5 & 17.5 & 82.5 & 15.0 & 85.0 & 12.5 & 87.5 \\
\hline
\end{tabular}

Table 4 Percentage of websites claiming at least one of diagnosis, treatment or efficacy for allergy/sensitivity or asthma, by search city

\begin{tabular}{lll}
\hline City & Allergy or sensitivity & Asthma \\
\hline Vancouver & 72.5 & 62.5 \\
Calgary & 67.5 & 60.0 \\
Edmonton & 65.0 & 55.0 \\
Ottawa & 65.0 & 55.0 \\
Kitchener & 62.5 & 45.0 \\
Hamilton & 60.0 & 57.5 \\
Toronto & 60.0 & 52.5 \\
Winnipeg & 57.5 & 40.0 \\
Montreal & 55.0 & 55.0 \\
London & 50.0 & 40.0 \\
\hline
\end{tabular}

Treated: Allergies" (naturalmedicine.mb.ca), "We treat both childhood and adult asthma" (selecthealthcentre. ca), and "Naturopathic medicine can treat a wide variety of conditions including: allergies" (albertanaturopath. com). Examples of claims of efficacy include: "Acupuncture works for bronchial asthma" (capitalacupuncture.ca), "Research studies show that children receiving Chiropractic care have improved: allergies [...]" (campbellcc.com) and "When treating asthma naturally [...] [i]f you are not in a weakened state, a colon cleanse is very beneficial". (health-and-natural-healing. com). In addition, although it was outside the scope of study, we noted comments suggesting that accepted medical interventions cause allergies and asthma, for example, "Recent research has confirmed that antibiotics and vaccinations are a cause of increased allergies and asthma" (homeopathic-clinic-lipa.com).

\section{DISCUSSION}

The results show that, overall, the majority of the CAM clinics studied claim they can either diagnose or treat both allergy/sensitivity and asthma. Indeed, it is reasonable to assume that the number of CAM providers actually administering such tests and treatments surpasses that which is advertised online, since some websites were very simple and did not expound significantly on services provided. These claims raise ethical issues, because evidence in support of many of the tests and treatments identified on the websites studied is lacking. ${ }^{23}$ For example, food-specific IgG testing was commonly advertised, despite the fact that the Canadian Society of Allergy and Clinical Immunology has recommended not to use this test due to the absence of a body of research supporting it. ${ }^{24}$ Live blood analysis, vega/electrodiagnostic testing, intravenous vitamin $\mathrm{C}$, probiotics, homeopathic allergy remedies and several other tests and 
Table 5 Twenty-seven examples of tests and treatments advertised for allergy, sensitivity or asthma on Canadian CAM clinic websites

Targeted condition indicated as follows: AL; AS; S

Muscle response testing (AL, S)

Acupuncture/acupressure (AL, AS, S) pH testing (AL, AS)

Neuromuscular sensitivity testing (S) Fish oil consumption (AL, S)

Nutritional supplements (AL, AS, S) Electrodermal testing (AL, S)

Sublingual immunotherapy (AL, AS) Drinking broths regularly (AL)

Subcutaneous immunotherapy (AL) Neural therapy (AL, AS)

Immunoglobulin G testing (AL, S) Vitamin and mineral injection (AL, AS)

Immunoglobulin E testing (AL) Bioresonance therapy (AL, AS)

AL,allergies; $A S$, asthma; CAM, complementary and alternative medicine; $\mathrm{S}$, sensitivity.

Electro acupuncture according to Voll (AL)

Bowen therapy (AL, AS)

Biofeedback analysis (AL, AS)

Ozone therapy (AL, S)

Homeopathic remedies (AL, AS, S)

Regular detoxification (AL, S)

Probiotics (AL, AS)

Adrenal extract (AL, AS)

Intravenous vitamin $\mathrm{C}(\mathrm{AL})$ treatments offered all lack substantial scientific evidence of efficacy. ${ }^{25-33}$ Some of the proposed treatments are so absurd that they lack even the most basic scientific plausibility, such as ionic foot bath detoxification. Very few of the tests and treatments offered are demonstrably clinically effective, and they include immunotherapy (effective in certain applications such as allergic rhinitis) ${ }^{34}$ and $\operatorname{IgE}$ testing (useful in combination with a clinical evaluation, but not as sometimes used by CAM practitioners in combination with invalid IgG testing). ${ }^{35}{ }^{36}$ Nevertheless, the presence of the term immunotherapy does not necessarily indicate scientifically legitimate or safe methods, as there are several unproven and potentially harmful forms of immunotherapy, including neutralisation, end point titration, etc. ${ }^{37}$

Perhaps most concerning is the fact that several proposed treatments for allergy, sensitivity or asthma are potentially harmful. These include intravenous hydrogen peroxide, spinal manipulation and possibly others. ${ }^{38} 39$ Furthermore, a negative effect of the use of invalid and inaccurate allergy testing is the likelihood that such testing will lead to alterations and exclusions in diets, which can subsequently result in malnutrition and other physiological problems. ${ }^{24}$ These risks are especially serious for growing children whose diets may be controlled by concerned parents convinced by their CAM providers that invalid testing is accurate. ${ }^{24}$ Paradoxically, and among young children particularly, prolonged unnecessary avoidance of certain foods can also increase the risk of developing true IgE-mediated food allergy. ${ }^{40} 41$

Some of this testing and treatment could result in higher healthcare resource usage, whereby, for example, blood analysis laboratories must deal with requests from naturopaths to test for clinically irrelevant factors. This would be costly and could hinder public health programmes. ${ }^{42}$ In these cases, financial exploitation is of the patient, as well as of the public health system and the taxpayer.

This study was not without limitations. First, the sample cannot be said to be entirely representative of major Canadian urban centres, because of the need to exclude Quebec City on the basis of the English search language. The extent of this English bias is significant but not measurable. Second, the approach of this study did not allow for more complex comparisons between jurisdictions, nor did it address related research questions, for example, an analysis of the extent to which advertising on clinic websites was targeted at different demographics. The popularity and regulation of these CAM disciplines vary between countries, so the results are not generalisable beyond Canada. Third, the search method excluded any text that was in image form, meaning that the presence of key words and claims may actually be higher than what was reported. Finally, it was impossible to measure how many individuals saw the advertisements and/or visited the clinics, and clinics were not assigned a relevance rank based on their location on the Google results page.

\section{CONCLUSION}

Increased regulation and government endorsement of CAM disciplines, such as the self-regulation of naturopaths in Ontario, British Columbia and Alberta, may have contributed to a growth in the perception of their legitimacy and efficacy as healthcare providers. ${ }^{43} 44$ Unfortunately, many of the interventions advertised by naturopaths, homeopaths, acupuncturists and chiropractors lack evidence of efficacy, as we found to be the case for allergy and asthma. In our view, the results speak to the need for a legal and/or policy response in order to prevent potential harm and financial exploitation. One strategy would be to increase the scope of advertising regulations and enforcement, and to explore the potential of applying evidence-based standards and restricting practitioners' ability to offer unproven tests and treatments. In addition, since allergy and asthma disproportionately affect younger generations, ${ }^{18}{ }^{22}$ policymakers should consider strategies that consider parents and guardians who may forego the public healthcare system in favour of using questionable CAM providers, potentially exposing minor children to harm. ${ }^{45}$ Ultimately, further research is needed to create and implement a 
new legal framework that will curb the questionable claims made by some CAM practitioners.

Acknowledgements The authors thank Carina Chiu, Nathaniel Brenneis, Sarah Denholm and Alessandro Marcon for their assistance in the data collection.

Contributors TC and BM conceived the study, designed the methods and coordinated data collection. BM and TC wrote the first draft of the paper. $\mathrm{SC}$ contributed to the writing of the paper. All authors critically revised the manuscript and approved the final version.

Funding The authors thank AllerGen NCE (the Allergy, Genes and Environment Network), a member of the Networks of Centres of Excellence Canada programme, as well as the Trudeau Foundation for funding this research.

\section{Competing interests None declared.}

Provenance and peer review Not commissioned; externally peer reviewed.

Data sharing statement The Excel data set is available from corresponding author on request.

Open Access This is an Open Access article distributed in accordance with the Creative Commons Attribution Non Commercial (CC BY-NC 4.0) license, which permits others to distribute, remix, adapt, build upon this work noncommercially, and license their derivative works on different terms, provided the original work is properly cited and the use is non-commercial. See: http:// creativecommons.org/licenses/by-nc/4.0/

\section{REFERENCES}

1. Public Health Agency of Canada. Complementary and Alternative Health; [about 1 screen]. Ottawa: Public Health Agency of Canada, (updated 1 April 2008; cited 5 July 2016). http://www.phac-aspc.gc. ca/chn-rcs/cah-acps-eng.php

2. The Fraser Institute. "Complementary and Alternative Medicine in Canada: Trends in Use and Public Attitudes, 1997-2006." Public Policy Sources, no. 87 (May 2007). https://www.fraserinstitute.org/ sites/default/files/ComplementaryAlternativeMedicine.pdf

3. Nahin RL, Barnes PM, Stussman BJ. Expenditures on complementary health approaches: United States, 2012. National Health Statistics Reports; 22 June 2016;95:1-11.

4. Fleming SA, Gutknecht NC. Naturopathy and the primary care practice. Prim Care 2010;37:119-36.

5. Hawk C, Ndetan H, Evans MW. Potential role of complementary and alternative health care providers in chronic disease prevention and health promotion: an analysis of National Health Interview Survey data. Prev Med 2012;54:18-22.

6. Shelley J, Clark M, Caulfield T. The face of chiropractic: evidence-based? Focus Altern Complement Ther 2015;20:13-22.

7. Caulfield T, Rachul C. Supported by science? What Canadian naturopaths advertise to the public. Allergy Asthma Clin Immunol 2011;7:14.

8. Pizzorno JE Jr, Murray MT. Textbook of natural medicine. Elsevier Health Sciences, 2012

9. Swannell C. Chiro and kids: time to make a stand. Sydney: Medical Journal of Australia. MJA InSight; [about 3 screens]. https://www.mja. com.au/insight/2016/16/chiros-and-kids-time-make-stand

10. Haggan M. Integrative medicine 'Health Fraud and Quackery'. Chatswood: Australian Journal of Pharmacy. Ajp.com.au; [about 2 screens]. https://ajp.com.au/news/integrative-medicine-health-fraudquackery/

11. Davey M. Chiropractors using 'unacceptable' false advertising, says board. The Guardian. 7 March 2016. http://www.theguardian.com/ australia-news/2016/mar/07/ chiropractors-using-unacceptable-false-advertising-says-board

12. Medew J. Doctors at war with chiropractors over treatment of babies and children. The Sydney Morning Herald. 28 April 2016. http://www.smh. com.au/national/health/doctors-at-war-with-chiropractors-over-treatmentof-babies-and-children-20160428-gohlc9.html\#ixzz477BygFnr

13. Weeks $\mathrm{C}$. Are we being served by the regulation of naturopaths? Not if patients are still being misled. The Globe and Mail. 28 April 2016. http://www.theglobeandmail.com/life/health-and-fitness/health/ canadian-naturopaths-need-to-follow-the-rules-if-they-wantregulation/article29785140/

14. Ismaila AS, Sayani AP, Marin M, et al. Clinical, economic, and humanistic burden of asthma in Canada: a systematic review. BMC Pulm Med 2013;13:1.
15. Pawankar R, Canonica GW, Holgate ST, et al., World Health Organization. White book on allergy 2011-2012 executive summary. World Allergy Organization, 2011.

16. Punekar YS, Sheikh A. Establishing the incidence and prevalence of clinician-diagnosed allergic conditions in children and adolescents using routinely collected data from general practices. Clin Exp Allergy 2009;39:1209-16.

17. Mallol J, Crane J, von Mutius E, et al., ISAAC Phase Three Study Group. The International Study of Asthma and Allergies in Childhood (ISAAC) phase three: a global synthesis. Allergol Immunopathol (Madr) 2013;41:73-85.

18. Gupta R, Holdford D, Bilaver L, et al. The economic impact of childhood food allergy in the United States. JAMA Pediatr 2013;167:1026-31.

19. Zuberbier T, Lötvall J, Simoens S, et al. Economic burden of inadequate management of allergic diseases in the European Union: a GA2LEN review. Allergy 2014;69:1275-9.

20. Lis DM, Stellingwerff T, Shing CM, et al. Exploring the popularity, experiences, and beliefs surrounding gluten-free diets in nonceliac athletes. Int $J$ Sport Nutr Exerc Metab 2015;25:37-45

21. Strom S. A big bet on gluten-free. New York Times. 17 February 2014. http://www.nytimes.com/2014/02/18/business/food-industrywagers-big-on-gluten-free.html

22. Asher MI, Montefort S, Björkstén B, et al., ISAAC Phase Three Study Group. Worldwide time trends in the prevalence of symptoms of asthma, allergic rhinoconjunctivitis, and eczema in childhood: ISAAC Phases One and Three repeat multicountry cross-sectional surveys. Lancet 2006;368:733-43.

23. Macdonald C, Gavura S. Alternative medicine and the ethics of commerce. Bioethics 2016;30:77-84.

24. Carr S, Chan E, Lavine E, et al. CSACl position statement on the testing of food-specific IgG. Allergy Asthma Clin Immunol 2012;8:12.

25. Normansell R, Kew KM, Bridgman A. Sublingual immunotherapy for asthma. Cochrane Database Syst Rev 2015;(8):CD011293.

26. Kang JH, Sim JY, Cho HS, et al. Clinical utility of live blood analysis. $J$ Korean Acad Fam Med 2001;22:70-7.

27. Katelaris $\mathrm{CH}$, Weiner JM, Heddle RJ, et al. Vega testing in the diagnosis of allergic conditions. The Australian College of Allergy. Med J Aust 1991;155:113-14.

28. McCarney RW, Linde K, Lasserson TJ. Homeopathy for chronic asthma. Cochrane Database Syst Rev 1999;(1):CD000353.

29. National Health and Medical Research Council (Australian Government). NHMRC information paper: evidence on the effectiveness of homeopathy for treating health conditions. National Health and Medical Research Council Website. 2016. http://www. nhmrc.gov.au/guidelines-publications/cam02

30. Gunaratne AW, Makrides M, Collins CT. Maternal prenatal and/or postnatal n-3 long chain polyunsaturated fatty acids (LCPUFA) supplementation for preventing allergies in early childhood. Cochrane Database Syst Rev 2015;(7):CD010085.

31. Osborn DA, Sinn JKH. Probiotics in infants for prevention of allergic disease and food hypersensitivity. Cochrane Database Syst Rev 2007;(4):CD006475

32. Fiocchi A, Pawankar R, Cuello-Garcia C, et al. World Allergy Organization-McMaster university guidelines for allergic disease prevention (GLAD-P): probiotics. World Allergy Organ J 2015;8:4.

33. Milan SJ, Hart A, Wilkinson M. Vitamin C for asthma and exercise-induced bronchoconstriction. Cochrane Database Syst Rev 2013;(10):CD010391.

34. Radulovic S, Calderon MA, Wilson D, et al. Sublingual immunotherapy for allergic rhinitis. Cochrane Database Syst Rev 2010;(12):CD002893.

35. Sicherer SH, Wood RA, American Academy of Pediatrics Section On Allergy And Immunology. Allergy testing in childhood: using allergen-specific IgE tests. Pediatrics 2012;129:193-7.

36. Stapel SO, Asero R, Ballmer-Weber BK, et al. Testing for IgG4 against foods is not recommended as a diagnostic tool: EAACI Task Force Report. Allergy 2008;63:793-6.

37. Cox L, Nelson H, Lockey R. Allergen immunotherapy: a practice parameter third update. J Allergy Clin Immunol 2011;127:S1.

38. Watt BE, Proudfoot AT, Vale JA. Hydrogen peroxide poisoning. Toxicol Rev 2004;23:51-7.

39. Ernst E. Adverse effects of spinal manipulation: a systematic review. J R Soc Med 2007;100:330-8.

40. Zeiger RS, Heller S, Mellon $\mathrm{MH}$, et al. Effect of combined maternal and infant food-allergen avoidance on development of atopy in early infancy: a randomized study. J Allergy Clin Immunol 1989;84:72-89. 
41. Du Toit G, Katz Y, Sasieni $P$, et al. Early consumption of peanuts in infancy is associated with a low prevalence of peanut allergy. J Allergy Clin Immunol 2008;122:984-91.

42. Times Colonist. Time to clarify health priorities. Victoria: Times Colonist, 2011.

43. Welsh S, Kelner M, Wellman B, et al. Moving forward? Complementary and alternative practitioners seeking self-regulation. Sociol Health IIIn 2004;26:216-41.
44. Wiese M, Oster C. 'Becoming accepted': the complementary and alternative medicine practitioners' response to the uptake and practice of traditional medicine therapies by the mainstream health sector. Health 2010;14:415-33.

45. Gerson J. The story of the tragic death of Ezekiel Stephan in 2012 begins with the tragic death of his grandmother in 1994. National Post. 10 June 2016. http://news.nationalpost.com/news/canada/ different-spin-on-health-inside-tragic-death-ezekiel-stephan 